\title{
Kalça Protezlerinde Loft Tasarım Aracı Kesit Değişimlerinin Gerilme Miktarı Üzerine Etkilerinin Íncelenmesi
}

\author{
Özkan Küçük ${ }^{1 *}$, Burak Öztürk ${ }^{2}$
}

Revize / Revised: 22/08/2020

Kabul / Accepted: 23/08/2020

\section{$\overline{\mathbf{O Z Z}}$}

Kalça eklemlerinde ileri derecede hasar oluşmuş hastalarda, kalça protezleri hasarlı eklemin yapay bir eklem olarak değiştirilmesi sonucunda kullanılmaktadır. Kalça protezi, kobalt krom veya titanyumdan imal edilen ana parçalar ile bunların eklemleştiği yerde plastik, metal veya seramik ara parçalardan oluşmaktadır. Kalça protezleri ve uygulamaları ile ilgili birçok tasarımsal problemin olduğu bilinmektedir. Bu sorunların çözümü hedeflenerek, endüstriyel tasarıma sahip üç farklı tip tasarım geometrisi seçilmiş ve Catia V5 programı ile modellenmiş̧ir. Bu protezlerin ve femurun montaj tasarımına etkiyen kuvvetler dikkate alınarak, emniyet katsayısı değerleri, sonlu elemanlar yönteminde, mühendislik gerilmeleri altında hesaplanmıştır. $\mathrm{Bu}$ hesaplamalar dikkate alındığında üç farklı endüstriyel tasarım içinden hacim oranı düşük olup gerilme miktarı diğer tasarımlara göre daha düşük olan tasarım tipi belirlenmiştir. Bu tasarımın 6 farklı kesiti içine alan bir loft tasarım aracı ile modellenebileceği gözlemlenmiş̧ir. Bu kesitlerde yer alan profillerin ölçü değişimi ana tasarım geometrisinden $1 \mathrm{~mm}$ ofset yapılarak modellenmiştir. Bu modelleme yapılırken Taguchi $\mathrm{L}_{8}$ deney tasarımı kullanılmıştır. Böylece her bir kesitin mukavemet ve hacim özelliklerine etkisi istatiksel yöntemler kullanılarak incelenmiştir. Tersine mühendislik ile tasarlanan bu protezlerin hacim miktarı 31285 ile $18438 \mathrm{~mm}^{3}$ ölçüleri arasında değişkenlik göstermektedir. Minimum hacim ve maksimum emniyet katsayısı elde edilebilmesi için gerekli tasarım seçimleri bu sonuçlar dikkate alınarak yapılmıştır. Minimum tasarım için deney tasarımı parametreleri $\mathrm{A}_{2}, \mathrm{~B}_{1}, \mathrm{C}_{1}, \mathrm{D}_{2}, \mathrm{E}_{1}, \mathrm{~F}_{1}$ olarak belirlenmiştir. Bu sonuçlara göre hacim $17975 \mathrm{~mm}^{3}$ ve gövde de oluşan maksimum gerilme $774 \mathrm{MPa}$ olarak bulunmuştur. Böylece hacim miktarı \%4 oranında azaltıllırken emniyet katsayısı ise $\% 8$ oranında artırılmıştır. Bu sonuçlar dikkate alındığında maksimum emniyet minimum hacim miktarı için elde edilmiştir.

Anahtar Kelimeler- Kalça Değiş̧tirme, Tasarım Optimizasyonu, Sonlu Elemanlar Yöntemi, Taguchi Yöntemi, Parametrik Tasarm

1*Sorumlu yazar iletişim: ozkan.kucuk@bilecik.edu.tr (https://orcid.org/0000-0002-4337-4454)

Metalurji ve Malzeme Mühendisliği Bölümü, Bilecik Şeyh Edebali Üniversitesi, Gülümbe Kampüsü, Merkez, Bilecik 2Iletişim: burak.ozturk@bilecek.edu.tr (https://orcid.org/0000-0002-1018-6545)

Metalurji ve Malzeme Mühendisliği Bölümü, Bilecik Şeyh Edebali Üniversitesi, Gülümbe Kampüsü, Merkez, Bilecik 


\title{
Investigation of the Effects of Loft Design Tool Cross-Section Changes on Stress Amount in Hip Prosthesis
}

\begin{abstract}
In patients with severe damage to the hip joints, hip prostheses are used as a result of replacing the damaged joint as an artificial joint. The hip prosthesis consists of main parts made of cobalt chrome or titanium and plastic, metal or ceramic spacers where they join. It is known that there are many design problems related to hip prostheses and their applications. With the aim of solving these problems, three different types of design geometry with industrial design were selected and modeled with the Catia V5 program. Considering the forces affecting the assembly design of these prostheses and femur, the safety coefficient values were calculated under engineering stress in the finite element method. Considering these calculations, among three different industrial designs, the design type whose volume ratio is low and the stress amount is lower than the other designs was determined. It has been observed that this design can be modeled with a loft design tool that includes 6 different sections. The size variation of the profiles in these sections is modeled by making $1 \mathrm{~mm}$ offset from the main design geometry. Taguchi $\mathrm{L}_{8}$ experimental design was used for this modeling. Thus, the effect of each section on the strength and volume properties has been analyzed using statistical methods. The volume of these prostheses designed with reverse engineering varies between 31285 and $18438 \mathrm{~mm} 3$. Necessary design choices were made by taking these results into consideration in order to obtain minimum volume and maximum safety coefficient. Experimental design parameters for the minimum design were determined as A2, B1, C1, D2, E1, F1. According to these results, the volume was found to be $17975 \mathrm{~mm} 3$ and the maximum stress on the body as $774 \mathrm{MPa}$. Thus, the volume amount was reduced by $4 \%$, while the safety factor was increased by $8 \%$. Considering these results, the maximum safety has been obtained for the minimum amount of volume.
\end{abstract}

Keywords- Hip Replacement, Design Optimization, Finite Elements Method, Taguch Method, Parametric Design 


\section{GIRIŞ}

Kalça protezlerinde ideal tasarım geometrisinin elde edilebilmesi için; ilk olarak hasta durum raporlarının ve literatürde yer alan analiz çalışmalarının birlikte ele alınması gereklidir. Total kalça artroplastisinde bir femoral stem kırığı nadir görülen bir komplikasyon olduğu birçok yazar tarafindan bildirilmiştir [1-4]. Avrupa'da çeşitli kurumlar bazı revizyon işlemleri bildirilmiştir ve yayınlanan raporlara göre son yıllardaki vaka sayısında bir artış gözlemlenmiştir [5-6]. Literatürde, özellikle modüler bileşenlerin kullanıldığı durumlarda, bu tür komplikasyonların çeşitli vakaları vardır. Kırık normal olarak modüler baş ara yüzünde oluşmaktayken, modüler boyun-gövde ara yüzeyinde de meydana gelmektedir. Uzun bir femur boynu kullanımı, hastanın aktivite seviyesi, gevşeme, varus dizilişi ve metalürjik ve tasarım faktörleri de dâhil olmak üzere kırık riskini artıran birçok faktör olduğu literatürde açıklanmıştır [4,7,8]. Farklı hasta durum raporlarında özellikle kalça protezi tasarım geometrisinde malzeme ve tasarım kaynaklı yorulma davranışına bağlı olarak kırılma vakaları görülmektedir. Ayrıca şimşsek çarpması gibi durumlarda da bir hasta durum raporu bildirilmiştir [9]. 77 yaşındaki bir sağlıklı kadın, femur sapının kırılmasından 6 ay önce minimal invaziv total kalça artroplastisi uygulanmıştır. Altı ay sonra, hasta ağır kaldırma sonrası femor ağrısı geçirmiştir ve sonuçlar femoral gövdede kırık olduğunu göstermiştir [10]. 1996 yılında 57 yaşında bir kadında sol kasık ağrısı ortaya çıkmıştır. Sonrasında kalça protezi uygulamasına karar verilmiştir. Ameliyat sırasında hastanın boyu $151 \mathrm{~cm}$ ve ağırlığı ise 59 kilogram olarak ölçülmüştür. Çimentolu protezin bir Centralign kalça protezi kullanılarak spinal anestezi altında gerçekleştirilmiştir. Ameliyattan 4 yıl sonra klinik semptomlar ortaya çıkmıştır [11]. Başka bir hastada ise ameliyattan altı yıl sonra bazı bölgelerde gövde ile çimento arasında kopma görülmüştür. Ameliyattan yedi yıl sonra ise kökün çimento örtüsünden ayrılması ve bazı bölgelerinde osteoliz genişlemiştir. 7,5 yıl sonra protez kullanılamayacak şekilde kırılması sonucunda revizyon yapılmasına karar verilmiştir [12].

Artroplasti uygulamalarında ortalama protez kullanım ömrü 15 yıl olarak belirlenmiştir. Bu bulgularda, 15 yıldan daha kısa sürede protezlerin kırılabildiği gözlemlenmiştir. Özellikle hastanın zamanla aldığı kilo, metalürjik zayıflık, bazı kazalar, vb. etkenlerin kullanım ömrünü azalttığı gözlemlenmiştir. Ayrıca birçok farklı tip tasarım geometrisine sahip kalça protezinin artroplasti uygulamalarında kullanıldığ 1 ve belirli bir standarda sahip olmadığı söylenebilir. Bu protezlerin literatürde yer alan sonlu elemanlar yöntemi ile analiz çalışmaları incelenerek protezlerin mukavemet özellikleri ile ilgili güncel çalışmalar rapor edilmiştir. Total veya parsiyel kalça replasmanı, kalça ekleminin parçalarının çıkarıldığı ve protez olarak bilinen yapay parçalarla yer değiştirdiği cerrahi bir prosedürdür. [13, 14] Titanyum bazlı alaşımlar, özellikle Ti-6Al-4V ve Ti-6Al-7Nb, eklem protezleri için halen en yaygın kullanılan malzemeler olup, ASTM standardında biyomalzeme olarak tescil edilmiştir. Başarısızlıktan kaçınmak mümkün olmasa da son çalışmalar bir implantın geliştirilmesinde yıkıcı başarısızlıklarını önlemek için tasarım araçlarına odaklanmıştır [15-17]. Total veya parsiyel kalça artroplastisi alanında sayısal yöntemler kullanılarak yapılan birçok çalışmanın amacı, ortopedik implantların genel güvenilirliğini arttırmaktır [18-20]. Böylece, Sonlu Elemanlar Metodu (FEM) ve Bilgisayar Destekli Tasarım (CAD) yöntemleri kullanılarak birçok farklı mühendislik problemin sonucu hesaplanabilmektedir. Protezin FEM analizi, Ti-6Al-4V alaşımından yapılmış bir model için düz bir yüzey üzerinde yavaş yürümeyi simule etmek için ABAQUS (Dassault Systèmes) yazılımı kullanılmıştır. Kalça implantının mekanik davranışının ön çalışmaları için, bir malzemenin doğrusal elastik davranışı, iki elastik sabitin bir fonksiyonu olarak analiz edilmiştir. Bir protezde yürüyüş sırasında üç eksen üzerinde oluşan kuvvetleri sonlu elemanlar yöntemi kullanılarak araştırmışlardır. Sonlu elemanlar ile stres analizi tekniği, statik yük analizine dayanan yapay kalça eklemlerindeki yük taşıyıcı bileşenlerde tasarım ve malzeme seçimini, hasta aktivitesi sırasında en yükssek yükü seçerek optimize etmek için kullanılmaktadır. Bu nedenle bir çarpma sırasında kalça protezi kullanıcısında oluşan kuvvetler sonlu elemanları kullanılarak hesaplanmıştır. Bu analiz sırasında uygulanan kuvvetler ve sabitlenen yüzeyler şekil 1'de verilmiştir [23]. Bu makalede literatürden farklı olarak, bir kaça protezinin tasarım geometrisini oluşturabilmek için, çoklu kesitten yüzey oluşturma işlemi olan loft tasarım aracındaki taslakların optimum ölçüleri araştırılmıştır. Tersine mühendislik ve Taguchi Metodu ayrıca bu araştırmada ideal tasarım geometrisinin modellenmesi için uygulanmıştır. 


\begin{tabular}{|c|c|c|}
\hline & $\begin{array}{l}\text { BŞEÜ Fen Bilimleri Dergisi } \\
7(2), 837-849,2020\end{array}$ & $\begin{array}{r}\text { BSEU Journal of Science } \\
\text { DOI: } 10.35193 / \text { bseufbd.706661 }\end{array}$ \\
\hline & & 58-7575 (http://dergipark.gov.tr/bseufbd) \\
\hline
\end{tabular}

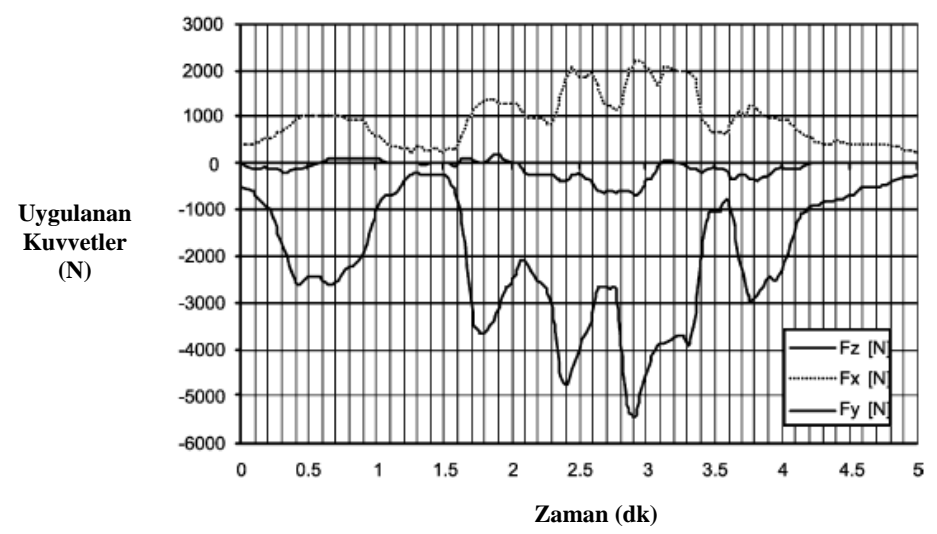

Şekil 1. Bir yere çarpma sonucunda kalça protezinde oluşan kuvvetler [23].

\section{MATERYAL VE METOT}

Endüstride kalça protezleri birçok farklı tip tasarım geometrisine sahip olarak üretilmektedir ve bu model geometrileri tasarım patentleri ile tescil edilmektedir. Şekil 2'de yer alan üç farklı tip protez tasarımları endüstride üretimi en yaygın olan geometri tipleri olduğu belirlenmiştir. Catia V5 programı tersine mühendislik aracı kullanılarak bu üç tasarım geometrileri modellenmiştir (Şekil 3).

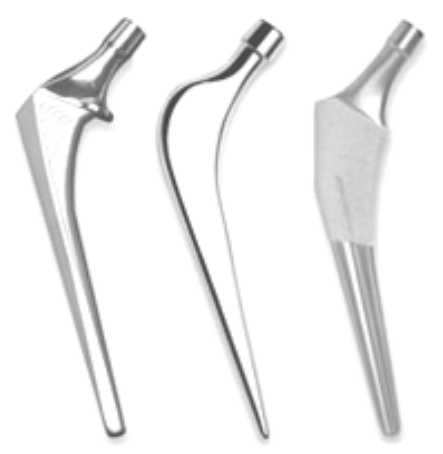

Şekil 2. Üç farklı tip tasarım geometrisine sahip protez tasarımları

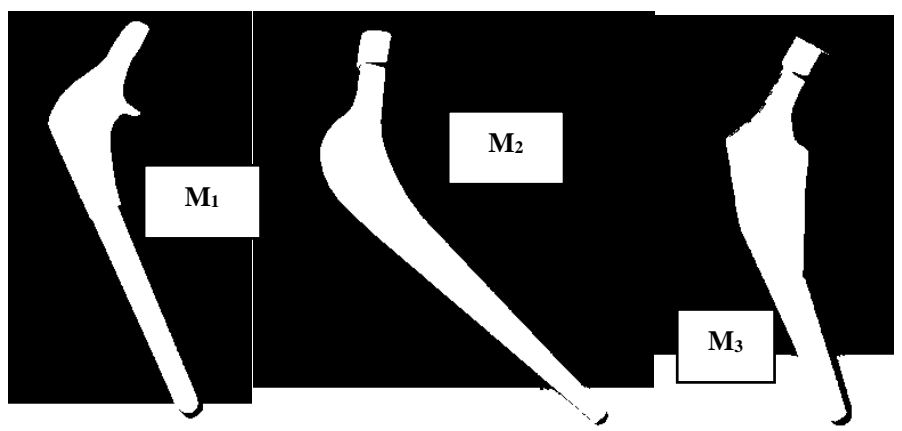

Şekil 3. Tasarımı yapılan üç farklı tip model geometrisi 


\begin{tabular}{|c|c|c|}
\hline & $\begin{array}{l}\text { BŞEÜ Fen Bilimleri Dergisi } \\
7(2), 837-849,2020\end{array}$ & $\begin{array}{r}\text { BSEU Journal of Science } \\
\text { DOI: } 10.35193 / \text { bseufbd.706661 }\end{array}$ \\
\hline $\begin{array}{l}\text { BiLECIK SEYYH EDEBALI } \\
\text { ONIVERSITES }\end{array}$ & & 58-7575 (http://dergipark.gov.tr/bseufbd) \\
\hline
\end{tabular}

Artroplasti uygulamalarında femur kemiğine kalça protezinin montajı özel bir çimento veya vidalı birleştirme yardımıyla yapılmaktadır. Sonlu elemanlar yöntemi kullanılarak kalça protezlerinin gerilme dağılım analizleri yapılabilmesi için; femur kemiği ile protezlerin montaj tasarımı yapılmıştır (Şekil 4 ). $\mathrm{Ti}_{6} \mathrm{Al}_{4} \mathrm{~V}$ ve kemik malzemelerinin ANSYS-Workbench malzeme kütüphanesinde tanımlanmış mekanik özellikleri Tablo 2' de yer almaktadir.

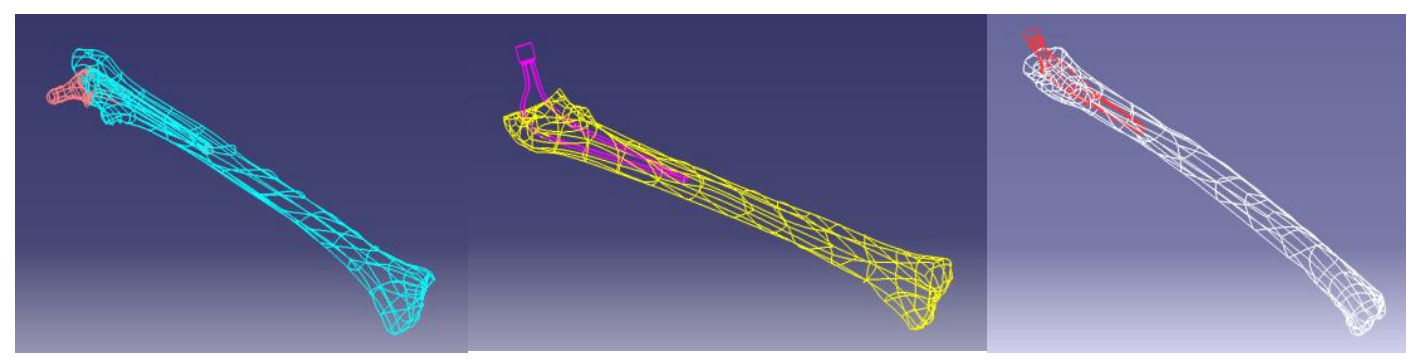

Şekil 4. Farklı tip tasarımların montaj tasarımı

Yürüyüş sırasında bir kalça protezinde dört farklı bölgede gerilmelerin oluştuğu rapor edilmiştir [23]. $\mathrm{Bu}$ kuvvetler referans alınarak femur ve kalça protezi üzerinde seçimler yapılmıştır (Şekil 5). Böylece sonlu elemanlar yöntemi ile gerçek koşullar altında analiz çalışması yapılabilecektir [24].

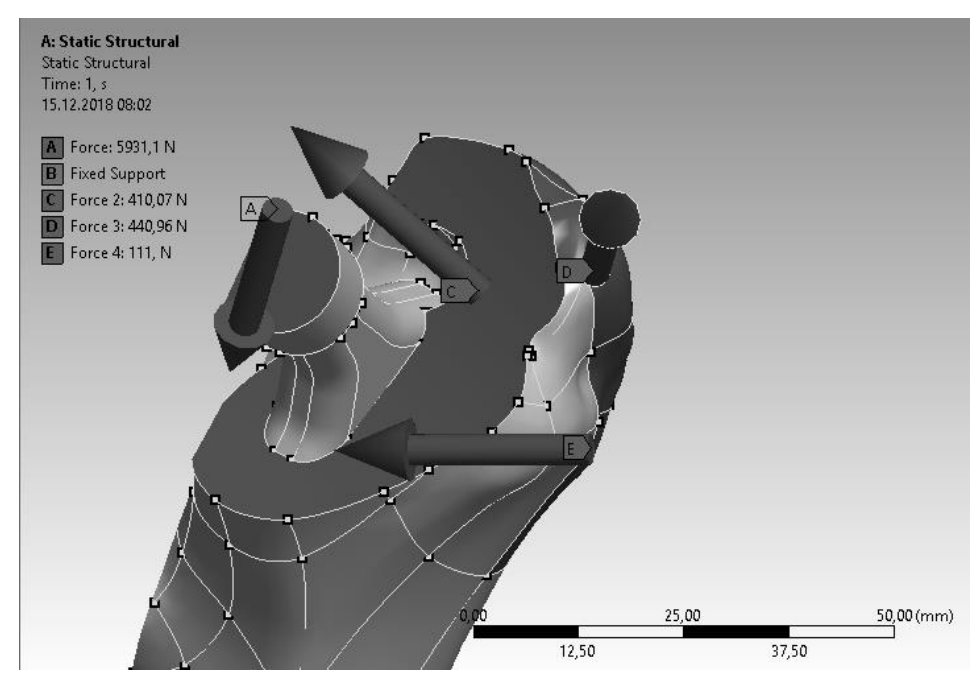

Şekil 5. Montajda tanımlanan kuvvetler

Tablo 1. Malzeme Özellikleri femur (solda), Ti6Al4V sağda (sağ)

\begin{tabular}{ccccc}
\hline & Özkütle & Young Modulü & Possion Oranı & $\begin{array}{c}\text { Akma } \\
\text { Dayanımı }\end{array}$ \\
\hline Femur & 1990 & 16200 & 0,38 & 114 \\
Ti6A14V & 4430 & $1 \mathrm{e}+05$ & 0,32 & 830 \\
\hline
\end{tabular}

Farklı geometrilere sahip kalça protezlerinin montaj tasarımları; belirlenen malzeme özellikleri tanımlanarak ve kuvvetler uygulanarak mühendislik gerilmeleri için ANSYS 15 programında maksimum gerilme miktarı hesaplamaları yapılmıştır. Her bir analiz çalışmasının gerilme dağılımı sonuçları femur ve protezler için şekil 6-8'de yer almaktadır. Bu sonuçlara göre protez üzerinde oluşan gerilme değişimlerinin; protez yüzeyi üzerinde farklılık gösterdiği belirlenmiştir. Protezlerin yüksek emniyet katsayısı sergilemesi istenirken, femur 


\begin{tabular}{|c|c|c|}
\hline & $\begin{array}{l}\text { BŞEÜ Fen Bilimleri Dergisi } \\
7(2), 837-849,2020\end{array}$ & $\begin{array}{r}\text { BSEU Journal of Science } \\
\text { DOI: } 10.35193 / \text { bseufbd.706661 }\end{array}$ \\
\hline & & $58-7575$ (http://dergipark.gov.tr/bseufbd) \\
\hline
\end{tabular}

emniyet katsayısının protezin altına düşmemesi için optimum tasarım geometrisinin seçiminin yapılması gereklidir.

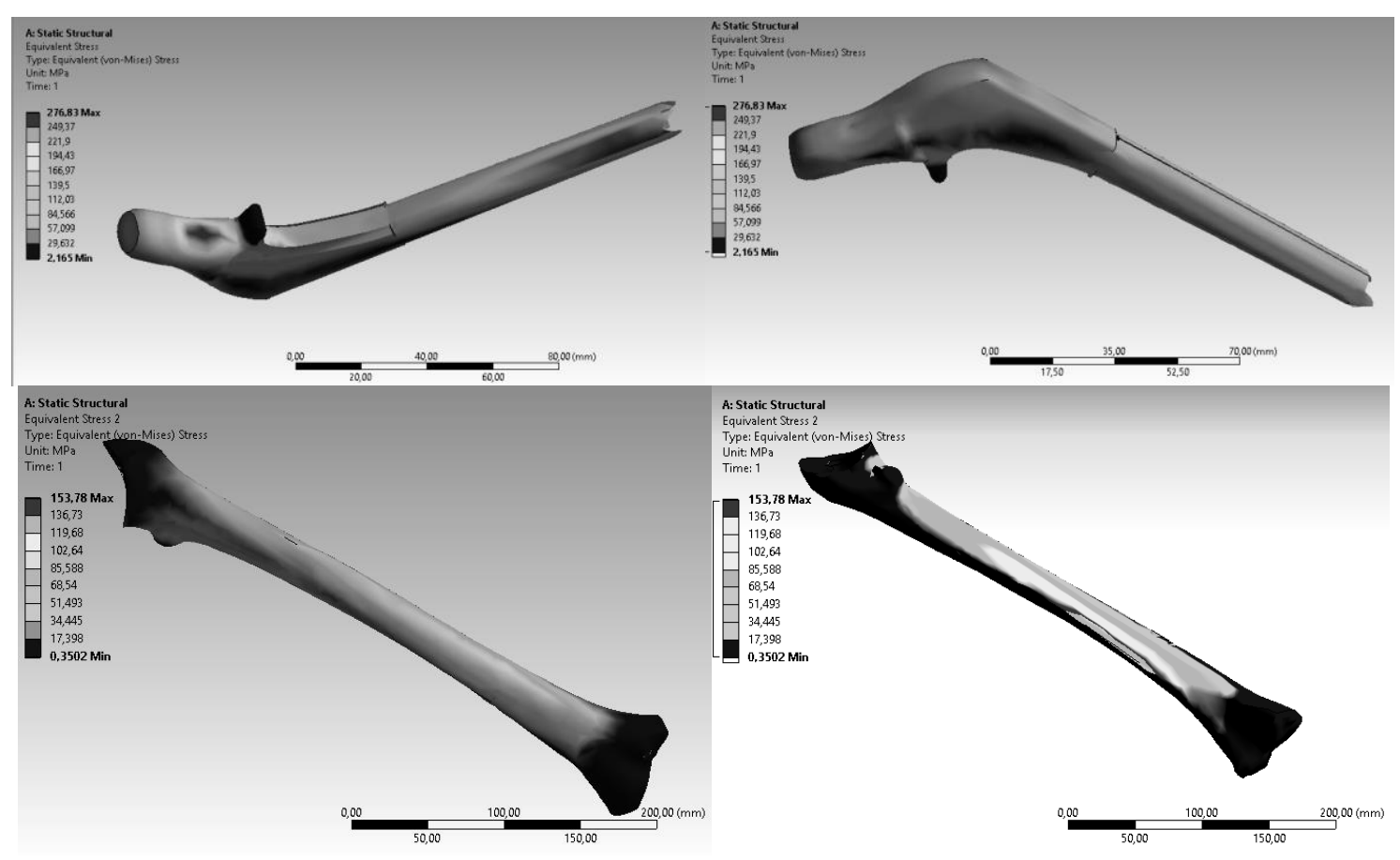

Şekil 6. $M_{1}$ için yüzeylerde oluşan gerilme dağılımı sonuçları

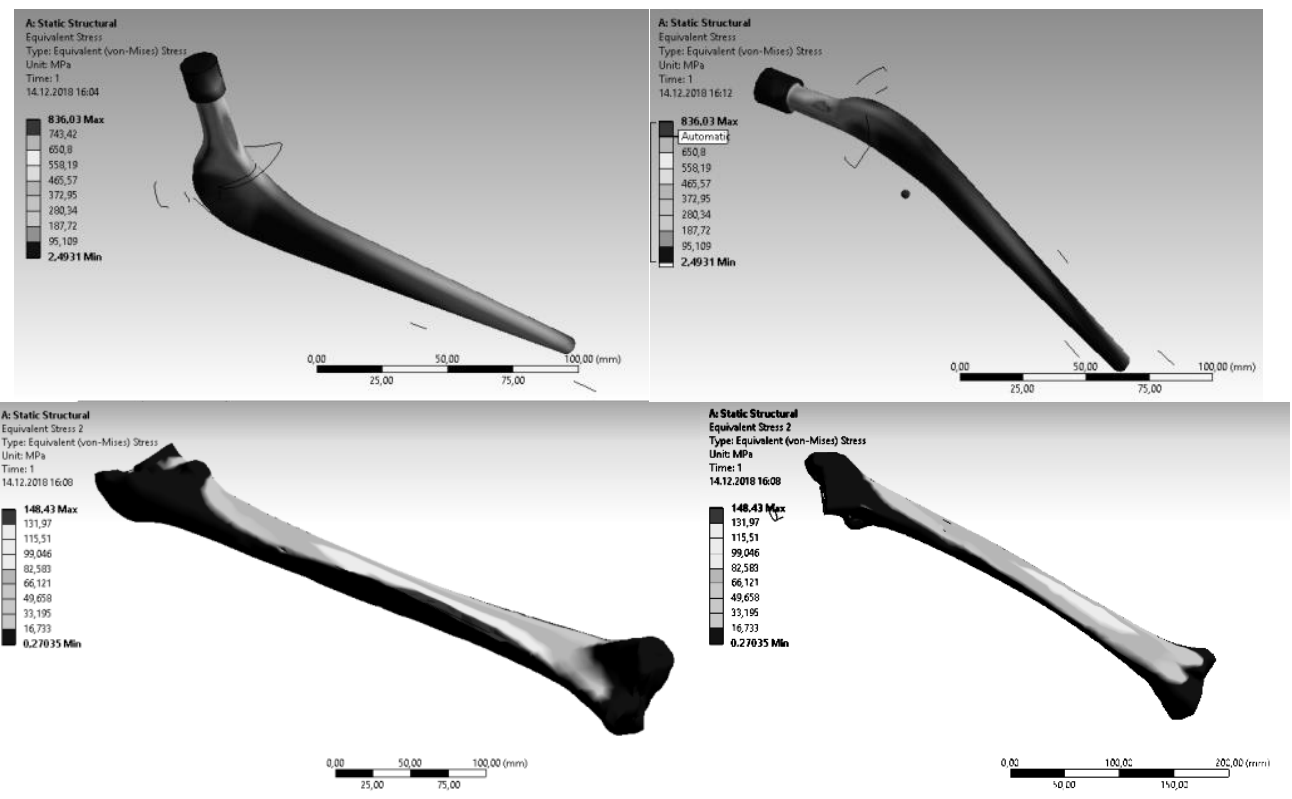

Şekil 7. $\mathrm{M}_{2}$ için yüzeylerde oluşan gerilme dağılımı sonuçları 


\begin{tabular}{|c|c|c|}
\hline & $\begin{array}{l}\text { BŞEÜ Fen Bilimleri Dergisi } \\
7(2), 837-849,2020\end{array}$ & $\begin{array}{r}\text { BSEU Journal of Science } \\
\text { DOI: } 10.35193 / \text { bseufbd.706661 }\end{array}$ \\
\hline 0 & & 58-7575 (http://dergipark.gov.tr/bseufbd) \\
\hline
\end{tabular}

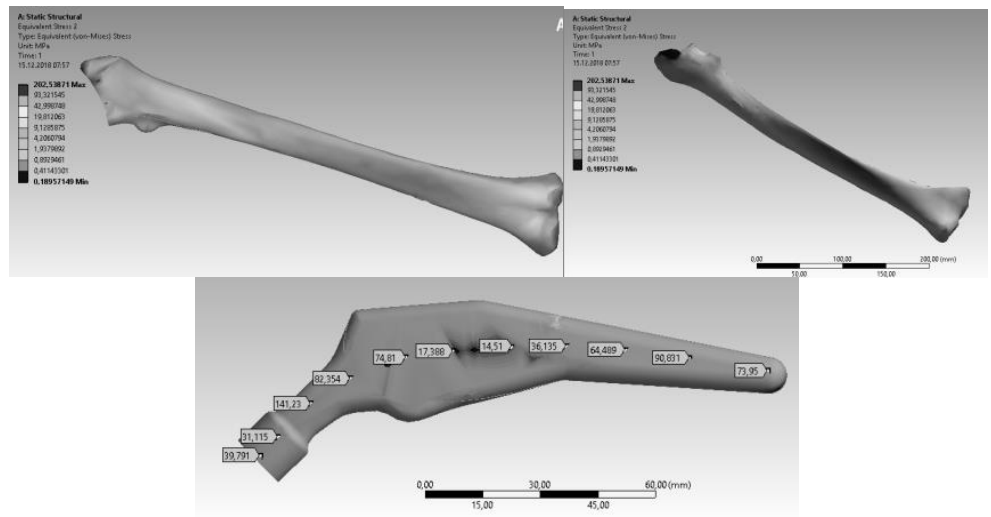

Şekil 8. $M_{3}$ için yüzeylerde oluşan gerilme dağılımı sonuçları

\section{TAGUCHİ VE ANOVA VARYANS ANALIZi}

Sonlu elemanlar yardımıyla yapılan analiz sonuçları incelendiğinde; gerilme dağılımlarının farklı değerlere sahip olduğu ve geometri yüzey alanlarında çok değişken değerler sahip olduğu ortaya çıkmıştır (Şekil 9). Üç farklı tasarımın gerilme dağılım sonuçları ele alındığında 1. Tasarımın hacim değeri en yüksek modeldir. Bununla birlikte bu geometrinin gerilme miktarı oldukça azdır. İkinci tasarımın hacmi nispeten 1. Tasarıma göre düşük olsa da 3. Tasarıma göre yüksektir. Fakat gerilme miktarı çok düşüktür. Üçüncü tasarımın gerilme miktarı çok yüksek olsa da hacim miktarı çok düşüktür. Bu tasarım geometrisinin üç farklı model geometrisi içinde en ideal geometri olduğu belirlenmiştir.

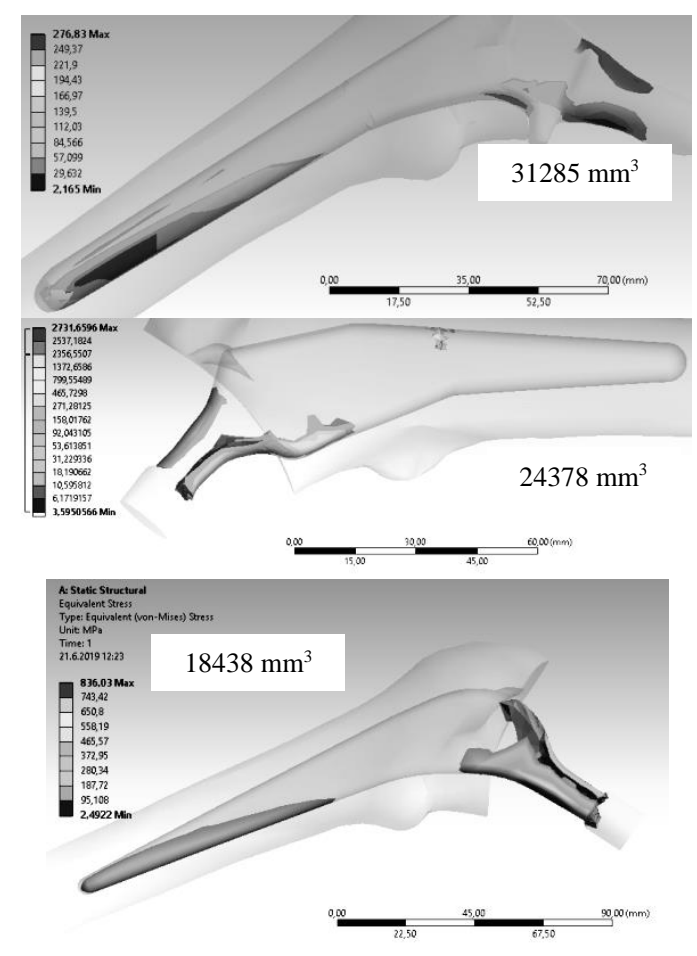

Şekil 9. Modeller için gerilme değişimlerini model dağılımı 
Bu tasarım geometrisi incelendiğinde "Loft" tasarım aracı yardımıyla 6 farklı kesit ile oluşturulabileceği gözlemlenmiştir (Şekil 10). Altı farklı kesitin her biri ofset araç çubuğuyla $1 \mathrm{~mm}$ kalınlaştırılabileceği, böylece emniyet katsayısının artırılabileceği düşünülmektedir.

Bununla birlikte hacmin optimum değerde olması için her bir kesitin mukavemet sonuçlarında etki oranlarının belirlenmesi kritik bir öneme sahiptir. Bilimsel araştırmalarda Taguchi yöntemi kullanılarak bir çok farklı optimizasyon araştırması yüksek güvenilirlik oranı ile tamamlanmıştır [25-29]. Bu çalışmada da Taguchi $\mathrm{L}_{8}$ ortogonal deney tasarımı kullanılarak parametrik tasarım yapılmasına karar verilmiştir. Böylece minimum hacim ve maksimum emniyet katsayısı elde edilebilecektir.

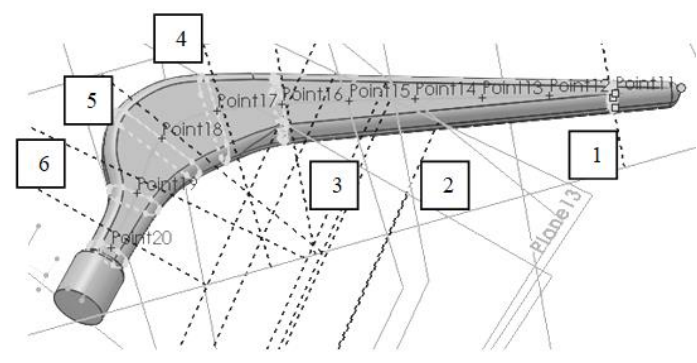

Şekil 10. Tasarımı oluşturan altı farklı kesit

6 farklı tasarım parametresi ve iki farklı seviyesi için Tablo 2'de yer alan Taguchi deney tasarımı oluşturulmuştur. Bu deney tasarımının birinci seviyesi her bir kesit profilinin ofset verilmemiş değeriyken, ikinci seviyesi ise dışa doğru $1 \mathrm{~mm}$ ofsetli şeklidir. Böylece her bir kesitin mukavemet ve hacim özelliklerine etkisi istatiksel yöntemler kullanılarak incelenebilecektir. Her bir deney tasarımı için geometriler modellenerek şekil 5 'de yer alan kuvvetler altında yeniden ANSYS programında analiz edilmiştir. Farklı tasarımların gövde ve sap kısımlarının ayrı ayrı olarak maksimum gerilme miktarları ölçülmüştür (Tablo 2.).

Tablo 2. L8 Taguchi Deney tasarımı parametreleri ve seviyeleri

\begin{tabular}{|c|c|c|c|c|c|c|c|c|}
\hline P1 & P2 & P3 & P4 & P5 & P6 & $\begin{array}{c}\text { Hacim } \\
\mathbf{( m m}^{\mathbf{3}}\end{array}$ & Gövde Ger. Mik. (MPa) & Sap Ger. Mik. (MPa) \\
\hline 1 & 1 & 1 & 1 & 1 & 1 & 18439 & 1015 & 148 \\
1 & 1 & 1 & 2 & 2 & 2 & 20336 & 1023 & 175 \\
1 & 2 & 2 & 1 & 1 & 2 & 19714 & 856 & 143 \\
1 & 2 & 2 & 2 & 2 & 1 & 21519 & 803 & 146 \\
2 & 1 & 2 & 1 & 2 & 1 & 21958 & 998 & 169 \\
2 & 1 & 2 & 2 & 1 & 2 & 18365 & 928 & 160 \\
2 & 2 & 1 & 1 & 2 & 2 & 22685 & 791 & 141 \\
2 & 2 & 1 & 2 & 1 & 1 & 16922 & 805 & 168 \\
\hline
\end{tabular}

Hacim ve Maksimum Gerilme Miktarı Değişimleri için kontrol faktörlerinin her kombinasyonu Taguchi deney tasarımında Sonlu Elemanlar Yöntemi ile ölçülür. Kontrol faktörlerinin optimizasyonunda S/N oranları kullanılır. Hacim miktarının ve Maksimum Gerilme Miktarının düşük olması ürün kalitesi, maliyeti ve ömrü açısından büyük bir öneme sahiptir. $\mathrm{S} / \mathrm{N}$ değerlerinin hesaplanmasında Eş.1,2 ve 3 kullanılmaktadır. Minitap programında Taguchi Analizi yapılarak şekil 11'de yer alan $\mathrm{S} / \mathrm{N}$ oranları hesaplanmıştır. Bu sonuçlar optimum tasarım seviyelerinin seçilmesinde bize yol göstermektedir. Minimum hacim ve maksimum emniyet katsayısı elde edilebilmesi için gerekli tasarım seçimleri bu sonuçlar dikkate alınarak yapılmıştır.

$$
\text { Nominal en iyidir : } S N_{N}=-10 \log \left(\overline{y^{2}} / S\right)
$$


En büyük en iyidir: $S N_{L}=-10 \log _{10}\left(\frac{1}{n} \sum_{i=1}^{n} \frac{1}{Y_{i}^{2}}\right)$

En küçük en iyidir: $S N_{S}=-10 \log _{10}\left(\frac{1}{n} \sum_{i=1}^{n} Y_{i}^{2}\right)$

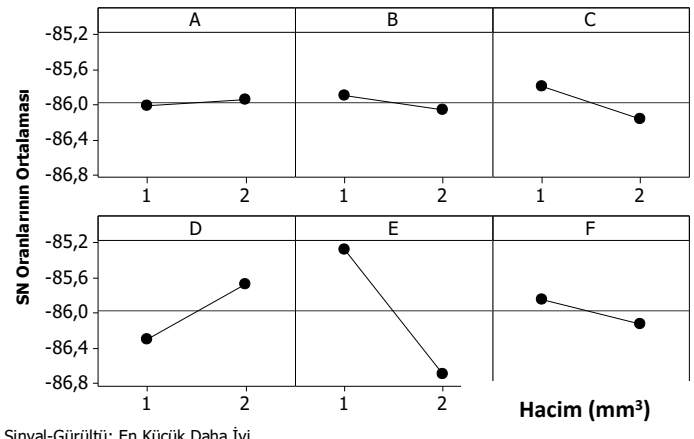

Sinyal-Gürültü: En Küçük Daha İyi

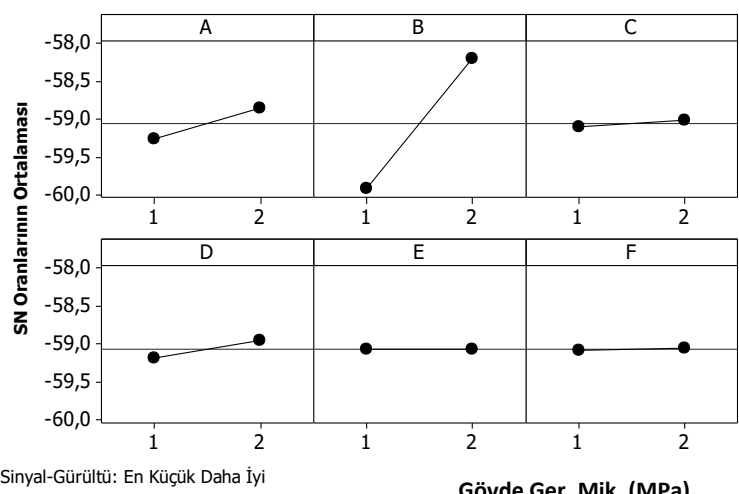

Sinyal-Gürültü: En Küçük Daha İyi

Gövde Ger. Mik. (MPa)

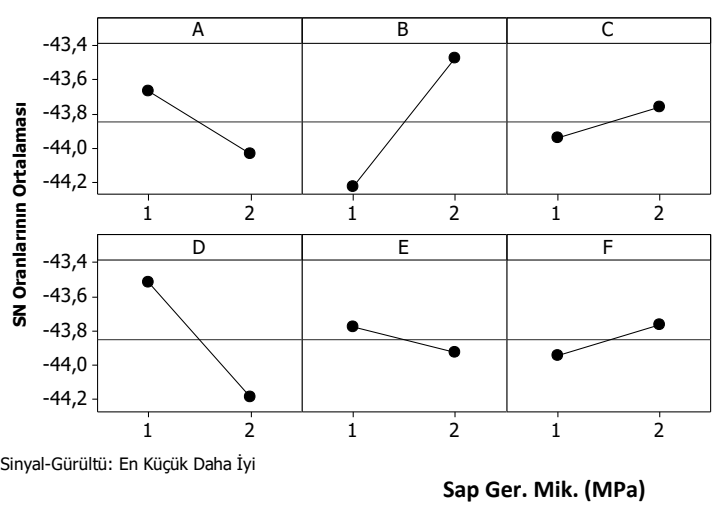

Şekil 11. Hacim Değişimleri, Gövde Gerilme Miktarları ve Sap Gerilme Miktarları için S/N oranları

Deney tasarımı bir çok farklı alanda optimum koşulların belirlenmesi için kullanılmaktadır [30,31]. Optimum tasarım için deney tasarımı parametreleri $\mathrm{A}_{2}, \mathrm{~B}_{1}, \mathrm{C}_{1}, \mathrm{D}_{2}, \mathrm{E}_{1}$ ve $\mathrm{F}_{1}$ olarak bulunmuştur. Bununla birlikte protezin sap ve gövde tasarımı için optimum deney tasarımı parametrelerinin seviyeleri farklılık göstermiştir. 
Tablo 2'de yer alan değerler dikkate alındığında gövdede oluşan gerilme miktarı daha fazla olduğu için tasarım yapılırken bu bölgede optimum koşulların dikkate alınmasının gerektiği gözlemlenmiştir. Böylece $A_{2}, B_{2}, C_{2}, D_{2}$, $E_{1}$ veya $E_{2}$ ve $F_{2}$ parametreleri ve seviyelerinin seçilmesinin gerektiği belirlenmiştir. Minimum hacim ve maksimum emniyet katsayısını bulmak için ise Anova Varyans analizi yapılmıştır. Çünkü, hacim ve gerilme miktarı seçiminde ortak olmayan seviyelerde \% etkinin dikkate alınması çok önemlidir ve bu yüzden Minitap programında varyans analizi yapılmış ve Tablo 3'deki sonuçlar elde edilmiştir.

Tablo 3. Varyans analizi sonuçları

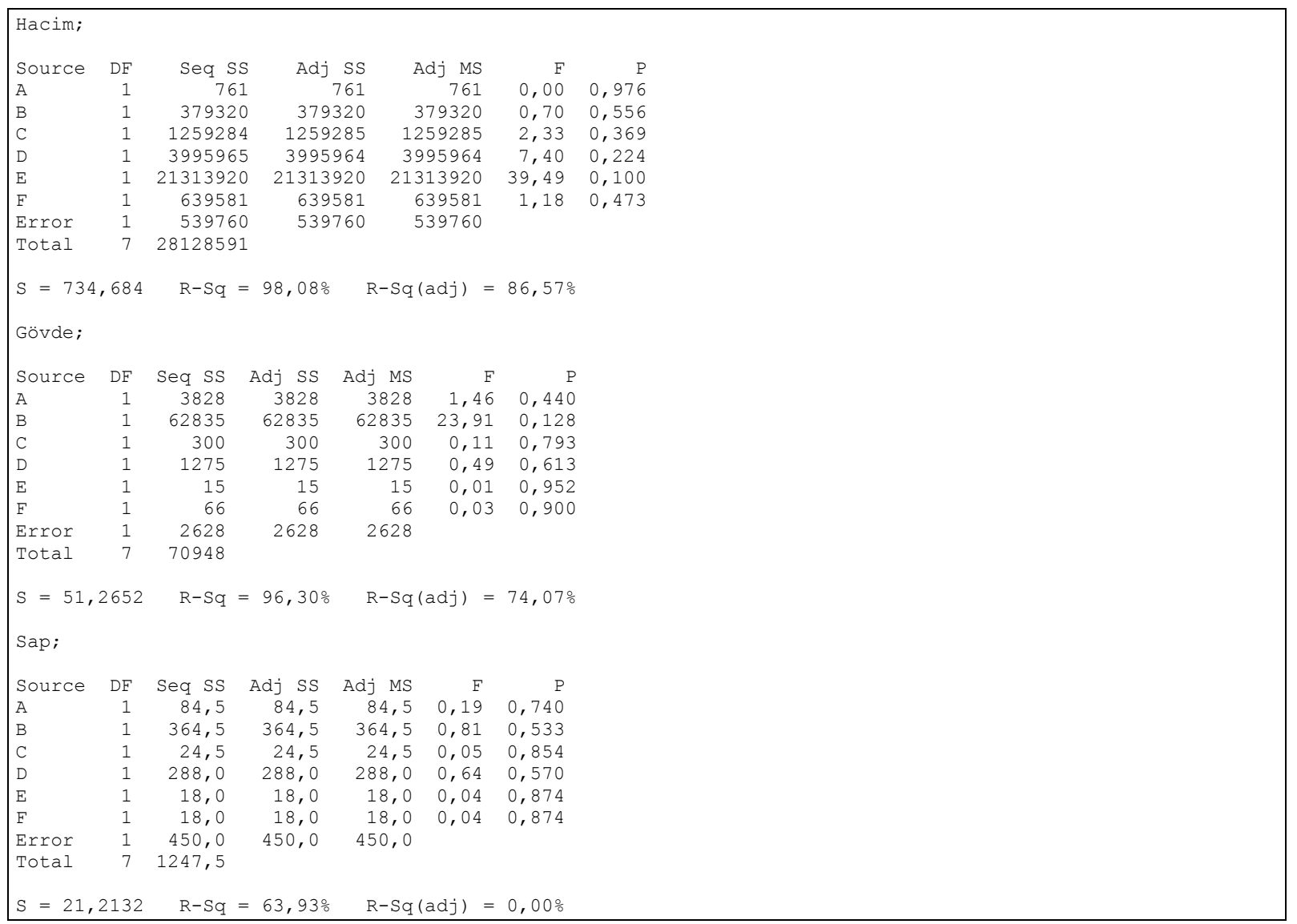

\section{SONUÇLARIN DEĞERLENDIRILIMESI}

Endüstride ve literatürde bir çok farklı tip protez geometrisi yer almaktadır. Bu yüzden bir çok farklı yöntem kullanılarak optimum tasarım elde edilebilmektedir. Bu analiz sonuçları ile gerilme miktarının yüksek olduğu bölgeler belirlenerek bu bölgeler mukavemet artırıcı tasarımsal değişikliklere tabi tutulacaktır. Böylece tasarımlar kırılma olasılığı yüksek olan bölgeler için güçlendirilebilecektir. Ayrıca gerilmenin az olduğu bölgelerde tasarım ağırlığı azaltılabilecektir. Bunun sonucunda tasarım hafifletilebilecektir. Farklı tip tasarım geometrilerinin gerilme dağılım grafikleri birbirinden farklı sonuçlar vermiştir. $M_{3}$ tasarımında gerilme miktarının daha az oluşacağı belirlenmiştir. $\mathrm{M}_{1}$ tasarımında ise özellikle sap kısmında gerilmenin çok fazla olduğu gözlemlenmiştir. Bu sonuçlar hasta durum raporlardaki kırılma şekilleri ile benzerlik göstermiştir [9, 10, 12]. $\mathrm{Bu}$ da sonlu elemanlar analizinin doğru bir şekilde yapıldığını göstermektedir. Kemikte oluşan gerilme sonuçları incelendiğinde $\mathrm{M}_{1}$ kemiğinde $153 \mathrm{MPa}, \mathrm{M}_{2}$ kemiğinde $148 \mathrm{MPa}$ ve $\mathrm{M}_{3}$ kemiğinde $202 \mathrm{MPa}$ maksimum gerilme gözlemlenmiştir 
Bu araştırmada, Taguchi Metodu kullanarak bir kalça protezinin tasarımına karar verilebileceği öngörülmüştür. Minimum hacim ve gövdede oluşan gerilmelerin optimum seviyeleri belirlenirken ilk olarak ortak parametre seviyeleri incelenir. Buna göre $A_{2}, D_{2}$ ve $E_{1}$ seçimi ortak parametre seviyeleridir. Bunun dişında kalan parametreler etki oranları dikkate alınarak yapılmıştır. Buna göre B parametresi incelendiğinde bu parametrenin gerilmeye etkisi hacimden daha fazladır. $\mathrm{Bu}$ yüzden $\mathrm{B}_{2}$ seviyesi seçilmelidir. $\mathrm{C}$ için ise hacim miktarına etkisi daha yüksek olduğundan $\mathrm{C}_{2}$ seviyesi seçilmelidir. $\mathrm{F}$ parametresinde de $\mathrm{C}$ 'de olduğu gibi hacim miktarına etkisi daha yüksek olduğundan $F_{1}$ seçilmelidir. Bu sonuçlar için hacim $17975 \mathrm{~mm}^{3}$ ve gövde de oluşan maksimum gerilme 774 Mpa dır. Sonuç olarak maksimum emniyet, minimum hacim miktarı için elde edilmiştir.

\section{TEŞEKKÜR}

Bu çalışma, Bilecik Şeyh Edebali Üniversitesi Bilimsel Araştırma Projeleri Komisyonu tarafından desteklenen 2018-01.BŞEÜ.03-04 numaralı proje kapsamında yürütülmüştür. Yazarlar, Bilecik Şeyh Edebali Üniversitesine mali desteklerinden dolayı teşekkür etmektedir.

\section{KAYNAKLAR}

[1] Dangles, C. J., Altstetter, C. J. (2010). Failure of the modular neck in a total hip arthroplasty. J Arthroplasty, 25 (7), 1169, 5-7.

[2] Sotereanos, N. G., Sauber, T. J., Tupis, T. T. (2013). Modular femoral neck fracture after primary total hip arthroplasty. J Arthroplasty, 28 (1), 196. 7-9.

[3] Morley, D., Starks, I., Lim J. (2012). A case of a C-Stem fracture at the head-neck junction and a review of the literature. Case Rep Orthop, Article ID 158604

[4] Baratz, M. D., Abdeen, A. (2014). Fracture of a tapered femoral neck after total hip arthroplasty. JBJS Case Connect, 4 (1), 1-4.

[5] Garellick, G, K€arrholm, J, Rogmark, C, Rolfson, O. (2012). Swedish Hip Arthroplasty Register: Annual Report; Available at: www.shpr.se/en/

[6] National Joint Registry for England. Report Wales and Northern Ireland. 7the11th Annual Report, 20102014. Available at: www.njrcentre.org.uk.

[7] Charnley J. (1975). Fracture of femoral prostheses in total hip replacement. A clinical study. Clin Orthop., 11:105-120.

[8] Galante, J. O. (1980). Causes of fractures of the femoral component in total hip replacement. J Bone Jt Surg Am., 62(4), 670-673.

[9] Lizano-Díez, X, Alentorn-Geli, E, León-García, A, Marqués-López, F. (2016). Fracture of the femoral component after a lightning strike injury: A case report. Acta Orthop Traumatol Turc, 51(1), 84-87.

[10] Benthien, J. P., \& Siepen, W. (2014). Early failure of a non-cemented femoral stem after minimal-invasive total hip arthroplasty: cause analysis and classification. Musculoskeletal surgery, 98(1), 77-80.

[11] Mulroy, W. F., Estok, D. M., Harris, W. H. (1995). Total hip arthroplasty with use of so-called secondgeneration cementing techniques. J Bone Joint Surg, 77(12),1845-52.

[12] Yamasaki, S., Masuhara, K., Fuji, T. (2006). Fracture of the precoated femoral component after cemented total hip arthroplasty, Journal of Orthopaedic Science, 11(3), 308-311.

[13] Park, J. B. (2000). Hip Joint Prosthesis Fixation-Problems and Possible Solutions. The Biomedical Engineering Handbook, Second Edition, CRC Press LLC, 46.1 - 46.3 
[14] Jeffrey, N. K. (2006). Total joint replacement in osteoarthritis. Best Practice \& Research Clinical Rheumatology, 20(1), 145-153.

[15] Griza, S., Zanon, G., Silva, E.P., Bertoni, F., Reguly, A., Strohaecker, T.R. (2009). Design aspects involved in a cemented THA stem failure case. Engineering Failure Analysis, 16(1), 512-520.

[16] Hernandez-Rodriguez, M. A. L., Ortega-Saenz, J. A., Contreras-Hernandez G..R. (2010). Failure analysis of a total hip prosthesis implanted in active patient. Journal of the Mechanical Behavior of Biomedical Materials. 3, 619-622.

[17] Paliwal, M., Allan, D. G., Filip, P. (2010). Failure analysis of three uncemented titanium-alloy modular total hip stems. Engineering Failure Analysis. 17(5), 1230-1238.

[18] Bennett, D., Goswami, T. (2008). Finite element analysis of hip stem designs. Materials \& Design. 29(1), 45-60

[19] Senalp, A. Z., Kayabaşı, O., Kurtaran, H. (2007). Static, dynamic and fatigue behavior of newly designed stem shapes for hip prosthesis using finite element analysis. Materials and Design, 28, 1577-1583.

[20] Niesłony, P., Grzesik, W., Laskowski, P., Sienawski, J. (2014). Numerical and Experimental Analysis of Residual Stresses Generated in the Machining of Ti6Al4V Titanium Alloy. 2nd CIRP Conference on Surface Integrity (CSI), Procedia CIRP, 13, 78-83.

[21] Katarina Colic, Aleksandar Sedmak, Aleksandar Grbovic, Uros Tatic, Simon Sedmak, Branislav Djordjevic, (2016), Finite Element Modeling of Hip Implant Static Loading, Procedia Engineering, 149, 257-262.

[22] Kayabaşı, O., Erzincanlı, F. (2006) Finite element modeling and analysis of new cemented hip prosthesis. Advances in Engineering Software, 37, 477-483.

[23] El'Sheikh, H. F., MacDonald, B. J., Hashmi, M. S. J. (2003). Finite element simulation of the hip joint during stumbling: a comparison between static and dynamic loading. Journal of Materials Processing Technology, 143-144, 249-255,

[24] Black, J., Hastings, G. (1998). Handbook of Biomaterial Properties, Chapman \& Hall, London., Springer US10.1007/978-1-4615-5801-9

[25] Nas E and Öztürk B. (2018). Optimization of surface roughness via the Taguchi method and investigation of energy consumption when milling spheroidal graphite cast iron materials. Mater Test, 60, 519-524.

[26] Öztürk, B, Uğur, L, Erzincanlı, F, Küçük, Ö. (2018). Optimization of Polyethylene Inserts Design Geometry of Total Knee Prosthesis". International Scientific and Vocational Studies Journal 2, 31-39

[27] Kara F and Öztürk B. (2018). Comparison and optimization of PVD and CVD method on surface roughness and flank wear in hard machining of DIN 1.2738 mold steel. Sensor Rev 2018; 39. https://doi.org/10.1108/SR-12-2017-0266

[28] Öztürk, B. ve Küçük, Ö., (2019). Bakır ve Pirinç Talaşı ile Takviye Edilmiş Boru Bağlantı Elemanlarının İki Farklı Üretim Türü İçin (SEC) Özel Enerji Tüketim Modeli. Politeknik Dergisi, DOI: 10.2339/politeknik.473105.

[29] Öztürk, B., Erzincanlı, F., Development of femoral component design geometry by using DMROVAS (design method requiring optimum volume and safety), www.emeraldinsight.com/0264-4401.htm7

[30] Kara, F., Takmaz, A., (2019). Optimization by the Taguchi method of effect on the surface roughness of cryogenic treatment applied to cutting tools, Material Testing, 61(11): 1101-1104. 


\begin{tabular}{|c|c|c|}
\hline & $\begin{array}{l}\text { BŞEÜ Fen Bilimleri Dergisi } \\
7(2), 837-849,2020\end{array}$ & $\begin{array}{r}\text { BSEU Journal of Science } \\
\text { DOI: } 10.35193 / \text { bseufbd.706661 }\end{array}$ \\
\hline $\begin{array}{l}\text { ECIK SSEYH EDEBAL } \\
\text { VIVERSITESI }\end{array}$ & & 58-7575 (http://dergipark.gov.tr/bseufbd) \\
\hline
\end{tabular}

[31] Kara, F., (2018). Optimization of surface roughness in finish milling of AISI P20+S plastic mold steel, Materials and Technology, 52(2):195-200. 